\title{
Implementation of Returning Farmers Database Set Using Characteristics Information And Local Environment Information
}

\section{Sun-Ae Park ${ }^{1}$ and Bong-Hyun Kim*2}

\author{
${ }^{1}$ Assistant Director, Division of Bigdata Strategy, Ministry of Agriculture Food and Rural Affairs, Sejong-si, \\ 30110, Republic of Korea \\ *2Professor, Department of Computer Engineering, Seowon University, Cheongju-si, 28674, Republic of Korea \\ *Corresponding author. Tel.: +82-10-2078-7808; Email address: bhkim@ seowon.ac.kr
}

Article History:Received:11 november 2020; Accepted: 27 December 2020; Published online: 05 April 2021

\begin{abstract}
In recent years, returning farms are attracting attention as a new way of life from urbanites who are about to retire. Returning farming means that the population living in the city leaves the city and continues a new form of life in rural areas. In other words, the fever of returning farming and returning villages is increasing, and the present is called the era of returning farming. As interest in returning farms increases, it is essential to provide accurate information for a successful return to farming life. Therefore, in this paper, a set of returned farmers database was constructed to provide information related to returning farmers with improved reliability and accuracy. To this end, personal characteristic information of returnees and local environmental information were linked. In addition, a set of databases for returning farmers was constructed using population movement statistics and agricultural management database. In this paper, data necessary for service development were selected and collected. In addition, a total of three types of service scenarios were created according to the type of use of returnees, and information on customized policy projects for returnees were constructed. Finally, an exploratory analysis of the collected data was conducted. In other words, refinement work was carried out to build the utilized database set, and the database set was constructed according to the purpose of use. As a result, the agricultural support information and the agricultural management body database were used based on the basic characteristic information of the returnees to provide selective customized information and establish a database set to improve reliability. Through this, it is possible to provide a customized service for anyone interested in returning to farming to easily access the farming information database set and obtain related information.
\end{abstract}

Keywords: Returning farmers, Database set, Characteristics information, Local environment information, Agricultural management DB.

\section{Introduction}

In the 1980s, when the industrialization era began, the phenomenon of de-ruralization occurred and the concentration of the population in the city was caused, and the socialization problem began to emerge. Currently, the urban population is causing de-urbanization, and the number of returning farmers is increasing. Despite the advantages of convenient urban life, cultural facilities, educational conditions, convenient residential environment, convenient transportation, and customized infrastructure, the number of returning farmers is increasing every year. Since the end of the 2000s, the number of returning homes and homes has been increasing rapidly. In 2008, economic activities in cities became difficult after the financial crisis, and baby boomers started to retire in earnest, and the government's support policy for returning to farming and returning to villages became an important factor[1].

Returned farmers and returnees have the potential as innovative talents in agriculture and rural areas. The growth rate of the young returnees in their $40 \mathrm{~s}(43.0 \%)$ is higher than that of the total returnees $(37.5 \%)$, which tends to spread to non-baby boomers. In addition, returnees have career experiences in various fields. In terms of job classification, self-employed workers were the most, followed by office workers, administrative, managerial, managerial, and technical workers. In terms of industry classification, manufacturing was the most, followed by construction, sewage/environment, education, publishing/broadcasting, finance, and public administration[2-3]. Compared to the 516,817 people in 2017, this is a decrease of 26,487 people. In particular, the number of returnees decreased for two consecutive years. There is also an analysis that the enthusiasm for returning farms and villages has peaked and has entered a downward trend. The number of the noble village population also decreased significantly. The number of returnees in 2018 was 472,474. It decreased by 5\% compared to 497,187 in 2017. These phenomena are analyzed as a result of not being able to settle in a new life due to returning farms or returning villages, or as a result of such fear. In the end, it is indispensable to provide accurate information necessary for returnees and villagers, and provide highly reliable customized information for returnees[4].

The reasons for returning to farming by urban residents are various factors such as government policy encouraging return to farming, suitability of residence given by the farmland, environmental factors, future economic prospects, and lifelong jobs without retirement. Because of these factors, young people and retirees are making a decision to return to farming. However, people who practiced returning to farming with vague expectations and fantasies often fail to adapt to rural life due to a realistic sense of gap. In addition, due to the lack of understanding of the natives, there are many cases where a conflict with local residents makes it

*Corresponding author: Bong-Hyun Kim 
impossible to live a successful return to farming and regrets returning to farming[5-6].

More than 10,000 households generate demand for return to farming every year, but related information is still insufficient during the preparation for return to farming. As interest in returning farms increases, it is essential to provide accurate information for a successful return to farming life. Therefore, in this paper, a set of returned farmers database was constructed to provide information related to returning farmers with improved reliability and accuracy. To this end, personal characteristic information of returnees and local environmental information were linked. In addition, a set of databases for returning farmers was constructed using population movement statistics and agricultural management database.

To this end, data necessary for service development were selected and collected. In addition, a total of three types of service scenarios were created according to the type of use of returnees, and information on customized policy projects for returnees were constructed. Finally, an exploratory analysis of the collected data was conducted. In other words, refinement work was carried out to build the utilized database set, and the database set was constructed according to the purpose of use. As a result, the agricultural support information and the agricultural management body database were used based on the basic characteristic information of the returnees to provide selective customized information and establish a database set to improve reliability.

\section{Existing research analysis}

As the social phenomenon of de-urbanization and the government's policy on returning to farms widen, the number of returnees is increasing. Various service models related to returning to farming have been developed and utilized to enrich life for such population movement. However, in the case of existing research and service models related to farming, many problems have been raised. In the case of information service related to cultivated items for returnees, when users select cultivated items and comparative items, comparative information on the number of farm households, area, facility area, road area, self-cultivation area, and lease area is provided for the item. However, there is a problem in which it is difficult to find the meaning of providing the information[7].

In the case of information for information on agricultural and forestry projects, even if there is a change in the age, cultivation scale, and item of the input item, errors often occur in that agricultural and forestry projects are guided around similar projects. This is because the list is prioritized, focusing on projects with a larger support size than the purpose of applying for policy projects. At least 40 guided agricultural and forestry projects are provided, which is fading the meaning of customized support policy services. In addition, it is difficult to understand clear standards for payment and related businesses, causing confusion among users. In the case of the agriculture and forestry project guide, there are many errors in the amount of support, and details that are difficult to understand in the qualification requirements are described. In addition, in the case of agriculture and forestry projects, most of the applications are applied through local governments, but the contact information of the person in charge of the Ministry of Agriculture and Food is listed instead of the person in charge of the local government, causing a lot of inconvenience. Among the problems of existing studies, there is a limitation that the differences in recommended results according to gender and age are not significantly different. To improve this, it is necessary to reflect factors that improve the discrimination and suitability of the recommendation results. In other words, to improve demographic characteristics, factors related to the characteristics of returning to farming, such as single-person households, couples, couples and children, themselves and children, and couples and parents, should be reflected. In addition, it is necessary to ensure discrimination and suitability by reflecting the type of furniture when returning home to the recommendation $\operatorname{logic}[8-10]$.

Second, when selecting a desired crop, a variety can be selected, but if there is no farming experience or knowledge about the crop, there is a limit to the difficulty in selecting a variety. In order to improve this, it is necessary to provide detailed information on the variety, such as farming skills and knowledge about crops required when selecting a variety. Third, there is a limitation in that the criteria for recommendation logic are ambiguous when recommending regions for desired crops. In order to improve this, when recommending a region, a standard for recommendation logic is required. That is, it is necessary to design a model that reflects the factors that users focus on among the factors that determine the region. It is necessary to develop a model that gives high weight to the factors that users focus on when choosing a region, such as the major regions where returnee farmers cultivate desired crops and regions where many returnee farmers of similar age group migrate[11].

In addition, there is a limitation in that the provision of detailed information on the desired region and crop is insufficient. In addition, there is a problem in that only simple information about crops and regions entered by the user is provided. As another problem, there is a limitation in providing information on the major crops of early farmers and the migration route of returnees based on their current residence. To improve this, it is necessary to design a model with different weights for the two factors when selecting a desired crop and a desired region. In addition, after searching for patterns using data mining techniques, it is necessary to provide 
processed information.

\section{Data grouping and validation}

In this paper, a set of returned farmers database was constructed to solve the problems raised in the existing farming information service model. In other words, in order to provide information related to returning farming with improved reliability and accuracy, a set of database of returning farming persons was finally constructed by using three types of information related to returning farming. To this end, a set of databases required to implement a service model for providing information necessary for returning farms was established by linking each other's personal characteristic information, regional environment information, population movement statistics, and agricultural management database.

For data utilization and design, by examining the current status of the classification of farmer groups in existing services, it was used as a basis for judging the succession of the existing method or the application of a new classification method when establishing a group of farmers to provide policy beneficiary information of similar agricultural management entities. To this end, through three approaches, we verified and analyzed the current status of the farming group typing of the existing service.

(1) Analysis of application progress of farmer grouping type of existing service

(2) Verification that detailed DB is established according to the criteria and purpose of grouping of farmers

(3) Verification that the result value is displayed according to the results of the grouping of farmers

First, the application progress of the existing service to the farmer grouping type was analyzed. To this end, the criteria for the classification of farmers were set based on a total of 14 items such as cultivation area (total, item, type, ownership, etc.), age, and item. Of these, values ranging from 8 to 64 sections were set. The criterion for setting the section value aimed to derive and apply the optimal number of sections in which the number of farmers can be uniformly distributed for each section. The section value with the smallest deviation rate of the average number of farmers between each section was applied. Recently, restructuring (scaling, specialization, etc.) is underway due to other business closures or leave of absence, such as the aging of farmers, but the management scale of most farmers is still concentrated on small and medium-sized enterprises. Therefore, it is necessary to reexamine the method of categorizing farmers focusing on uniform distribution. Figure 1 shows the distribution map of the existing types of farmers. As shown in Figure 1, the classification of farmers centered on the even distribution is not applied, showing an extreme left-biased distribution map. In other words, it is necessary to apply the method of grouping farmers based on an understanding of the characteristics of agricultural cultivation area.

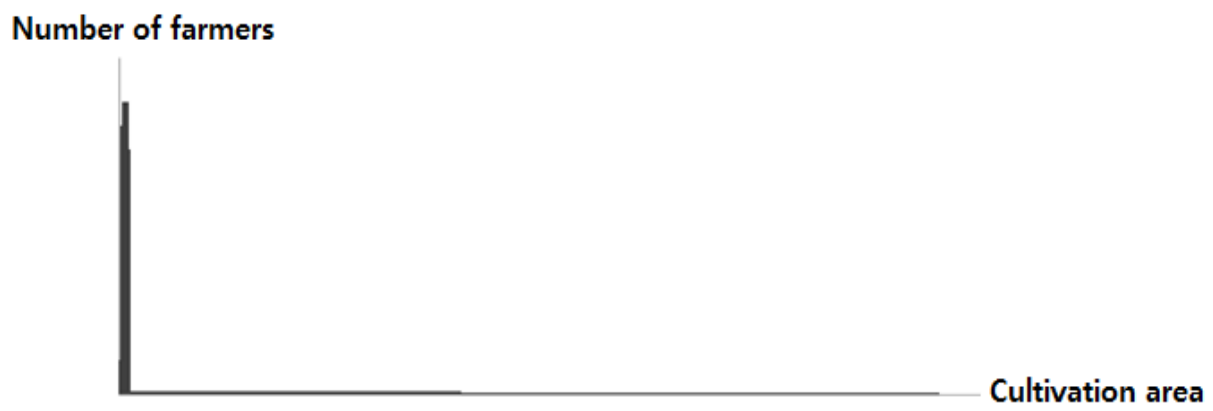

Figure 1 Existing farmer type distribution map

Second, it is necessary to verify detailed DB related to farmer grouping types. To verify the detailed DB, the existing DB for two items (apples and pears) was constructed according to the original purpose, and farmers verified the distribution status according to the set section value. As a result of verifying the apple item, as a result of verifying the distribution of farmers according to the set section value, it was confirmed that the section value was incorrectly set, such as $69.1 \%$ of apple cultivation farmers in the 23 section. In addition, the cultivation area section was widely distributed ( 23 sections), resulting in an error in the results. For example, when the age group, which is one of the group variables for the classification of farmers, was merged with condition (AND), there were cases where farmers did not exist or only a few exist under certain conditions. As for the result of verifying the pear item, it was confirmed that the section value was incorrectly set, such as $20.9 \%$ of pear farmers in the 23 section, like apples. In other words, under certain conditions, there were cases where there were no farmers or only a few farmers existed. Figure 2 shows the detailed DB verification results for the grouping of farmers by item for apples and pears. 


\begin{tabular}{|c|c|c|c|c|c|c|c|c|c|c|c|c|c|c|c|c|c|c|c|c|c|c|}
\hline 1 & 2 & 3 & 4 & 5 & 6 & 7 & 8 & 9 & 10 & 11 & 12 & 13 & 14 & 15 & 16 & 17 & 18 & 19 & 20 & 21 & 22 & 23 \\
\hline \multirow[t]{6}{*}{10 or } & $100=$ & $160 \approx$ & $230 \%$ & $300 \approx$ & $390=$ & $470=0$ & $550=\approx$ & $670 \approx$ & $810 \%$ & $950 \approx$ & 1060 & $1200=$ & $1400=$ & $1590=$ & $1830=$ & $2040=$ & 2310 & $2670=$ & $3110 \approx$ & $3710=$ & $4900=$ & 5 \\
\hline & & & & & & & & & & & & & & & & & & & & & & 1 \\
\hline & & & & & & & & & 2 & 3 & & 2 & 4 & 2 & 2 & 6 & 9 & 2 & 9 & 8 & 12 & 174 \\
\hline & 2 & & & & 6 & 1 & 3 & 2 & 5 & 3 & 7 & 7 & 7 & 18 & 10 & 15 & 21 & 29 & 36 & 48 & 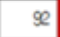 & 831 \\
\hline & 2 & 2 & 3 & 3 & 7 & 7 & 8 & 18 & 22 & 17 & 19 & 37 & 45 & 42 & 41 & 57 & 64 & 96 & 118 & 162 & $2 \pi 2$ & 2.914 \\
\hline & 9 & 7 & 16 & 35 & 30 & 31 & 28 & $\circledast$ & 59 & का & 96 & 121 & 193 & 198 & 233 & 200 & 20 & 352 & 462 & ๘का & 1,023 & 10,806 \\
\hline \multirow[t]{5}{*}{1} & 16 & 19 & 20 & 48 & 46 & 68 & 87 & 112 & 118 & 158 & 100 & 218 & 403 & 300 & 422 & 300 & $\infty$ & $\pi 9$ & 809 & 1.119 & 1.837 & 17,727 \\
\hline & 14 & 16 & 29 & 35 & 49 & 52 & 55 & 9 & 101 & 126 & 137 & 191 & 267 & 256 & 329 & 309 & 355 & 521 & 618 & 841 & 1,356 & 11,494 \\
\hline & 9 & 10 & 10 & 10 & 14 & 16 & 15 & 31 & 41 & 49 & $\infty$ & ผ5 & 119 & 116 & 127 & 128 & 141 & 213 & 200 & 316 & 487 & \begin{tabular}{|l}
3.527 \\
\end{tabular} \\
\hline & & 1 & & 1 & & 2 & 1 & 2 & 1 & 5 & 1 & 1 & 12 & 9 & 9 & 9 & 6 & 10 & 10 & 23 & 36 & 219 \\
\hline & & & & & & & & & 1 & & 1 & & & & & & & 1 & 2 & 1 & 1 & 13 \\
\hline 1 & 52 & 55 & 87 & 132 & 152 & 177 & 197 & 325 & 350 & 427 & 400 & 60 & 1,050 & 1,021 & 1,213 & 1,123 & 1,35 & 1,943 & 2204 & 3149 & 5155 & 87,706 \\
\hline 000 & 008 & 008 & 0.13 & 02 & 02 & 0.3 & 03 & 0.5 & 0.5 & 0.6 & 0.7 & 09 & 15 & 15 & 18 & 1.6 & 19 & 28 & 33 & 46 & 7.5 & Q9.1 \\
\hline
\end{tabular}

$<$ Apple item detailed DB verification result $>$

\begin{tabular}{|c|c|c|c|c|c|c|c|c|c|c|c|c|c|c|c|c|c|c|c|c|c|c|}
\hline 1 & 2 & 3 & 4 & 5 & 6 & 7 & 8 & 9 & 10 & 11 & 12 & 13 & 14 & 15 & \begin{tabular}{|l|}
16 \\
\end{tabular} & 17 & 18 & 19 & 20 & 21 & 22 & 23 \\
\hline \multirow[t]{5}{*}{100} & $100 \pi$ & $160=$ & $230=$ & $300 \%$ & $390 \%$ & $4 \pi 0=$ & $550 \mathrm{~m}$ & 6700 & $810=$ & $960 \mathrm{~m}$ & 1060 & $1200=$ & $1400=$ & 1990 & 1830 & $2040 \times$ & 2310" & $26 \%$ & 3110" & $3710=$ & $4900=$ & $5130=$ \\
\hline & & & & & & & & & & & & & & & & & & & & & & \\
\hline & & 1 & & & & & 2 & 2 & & 1 & 3 & 1] & 2 & & 3 & 1 & 8 & 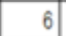 & 3 & 10 & 8 & 19 \\
\hline & & & 1 & 1 & 3 & 3 & 2 & 6 & 2 & 7 & 9 & 15 & 8 & 15 & 16 & 12 & 24 & 28 & 19 & 40 & 42 & 107 \\
\hline & 1 & 1 & 4 & 2 & 8 & 7 & 13 & 19 & 34 & 30 & 35 & 81 & 32 & 45 & 55 & 54 & 60 & 67 & 87 & 112 & 141 & 352 \\
\hline 1 & 5 & 12 & 10 & 23 & 43 & 53 & 68 & 84 & 128 & 165 & 142 & 278 & 100 & 210 & 240 & 232 & 246 & 204 & 319 & 358 & 498 & 1220 \\
\hline \multirow[t]{5}{*}{1} & 13 & 21 & 36 & 67 & 89 & 108 & 190 & 217 & 262 & 300 & 342 & 600 & 233 & 418 & 478 & 509 & 545 & 588 & $\dddot{33}$ & 674 & 898 & 2,028 \\
\hline & 15 & 26 & 24 & 50 & 79 & 90 & 164 & 164 & 245 & 273 & 294 & 488 & 216 & 37 & 396 & 448 & 510 & 481 & 540 & 551 & 603 & 1,215 \\
\hline & 2 & 9 & 15 & 10 & 33 & 45 & 48 & 63 & 92 & 109 & 121 & 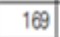 & 74 & 127 & 151 & 123 & 170 & 159 & 149 & 143 & 197 & 317 \\
\hline & & & & 2 & 3 & 5 & 3 & 3 & 10 & 7 & 5 & 14 & 2 & 4 & 8 & 4 & 5 & 11 & 7 & 10 & 12 & 15 \\
\hline & & & & & & & & & & & & & 1 & 1 & & & 1 & 1 & 1 & 1 & 1 & 5 \\
\hline 2 & 36 & 70 & 90 & 155 & 258 & 320 & 490 & 558 & 773 & 958 & 951 & 1.646 & 608 & 1,197 & 1,346 & 1,333 & 1,509 & 1,635 & \begin{tabular}{|l|l|}
1,758 \\
\end{tabular} & 1,809 & 2,400 & 5320 \\
\hline $0 a$ & 014 & $0 Z$ & 0.55 & 06 & 10 & 13 & 19 & 22 & 30 & 37 & 37 & 64 & 26 & \begin{tabular}{|l|}
47 \\
\end{tabular} & 53 & 54 & 61 & 64 & 69 & 74 & 96 & 209 \\
\hline
\end{tabular}

$<$ Pear item detailed DB verification result $>$

Figure 2 Detailed DB verification results for apples and pears

Finally, the expression of the result value according to the result of the grouping type of farmers was verified. In 2017, conditions were controlled (existing service inquiry, existing DB), and input information such as cultivation area and age for a specific item was changed, and the number of beneficiaries of the policy expressed and the number of farmers in the DB were compared. As a result of comparing the information displayed by changing the cultivation area and age of three items (apples, pears, rice), the result value reflects the established section information such as the cultivation area, rather than expressing information on the beneficiary policy of similar agricultural management entities. In addition, it was analyzed that relevant information is provided only on the basis of items.

\section{Database set implementation}

In this paper, a data-based service input model for returnees was implemented to analyze the problems of existing services and improve them so that they can settle their new life. To this end, a database set for returnee farmers was established to provide customized policy and support information with improved reliability. In other words, a set of returned farmers database was established by linking population movement statistics and agricultural management database based on personal characteristics of returnees and regional environmental information. Figure 3 shows the three input information databases that were used in connection to build a database set for returnees.

In order to provide policy business information according to similar management entity policy business information and user selection conditions, it was constructed so that the agricultural management entity registration number inquiry method, keyword search method, and condition search method input information can be classified. In addition, it was designed to change the DB used according to the usage behavior of the returnees. In other words, the DB used to provide policy information varies according to the three usage methods, and the DB configuration for this can be established as a core database set of the returning farm support service model. Table 1 shows the mechanism of results provided according to the input information. 


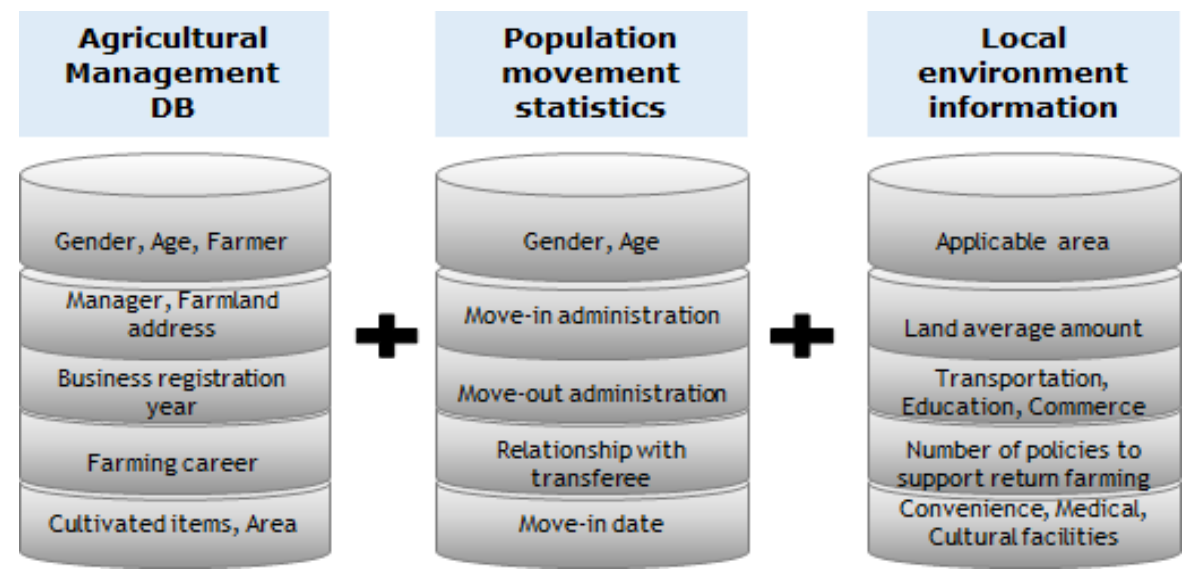

Figure 3 Design of input information database connection

Table1 Mechanism for providing results according to the type of input information

Input information

\begin{tabular}{|c|c|}
\hline $\begin{array}{l}\text { Agricultural management } \\
\text { registration number }\end{array}$ & $\begin{array}{l}\text { (1) Providing information on policy projects that management entities } \\
\text { similar to users have received based on registration information of } \\
\text { agricultural management entities (item, area, age, farming experience) }\end{array}$ \\
\hline Keyword search & (2)Display matching policy support projects through index search \\
\hline Condition search & $\begin{array}{l}\text { (3) Display of matching policy support projects through search for personal } \\
\text { information of users by farmers, corporations, and non-farmers and } \\
\text { conditions for specific items } \\
\text { (4) Based on user personal information, providing policy business } \\
\text { information to which business entities similar to users have benefited }\end{array}$ \\
\hline
\end{tabular}

To build a database set for returning farmers to implement customized return policy and support information provision service model, the process was divided into three stages. First is the data selection and collection stage. In the data selection and collection stage, data necessary for service development is selected and collected. In other words, it is the step of defining and collecting collected data to configure DB suitable for basic service concept.

Second is the service scenario configuration step. In the service scenario configuration stage, a total of three types of service scenarios were created according to the type of use of returnees. Through this, it is the step of providing customized policy and support information for returnees. At this time, the generated scenario is an agricultural management entity registration number input, keyword search, and condition search. In-out information structuring according to the service scenario created in the service scenario configuration stage was also carried out.

Third is the step of building a database set using data purification and model. In the stage of data purification and database set construction using models, exploratory analysis was conducted on the collected data. In addition, refinement work was carried out to establish the utilization DB set, and finally, a returnee database set was constructed according to the purpose of utilization. At this time, the established database set includes a farming activity-based support project information service DB, a customized policy project DB, and a farmer tangible DB. Figure 4 shows the configuration diagram of the returnee database set that will be finally used as a service model. 


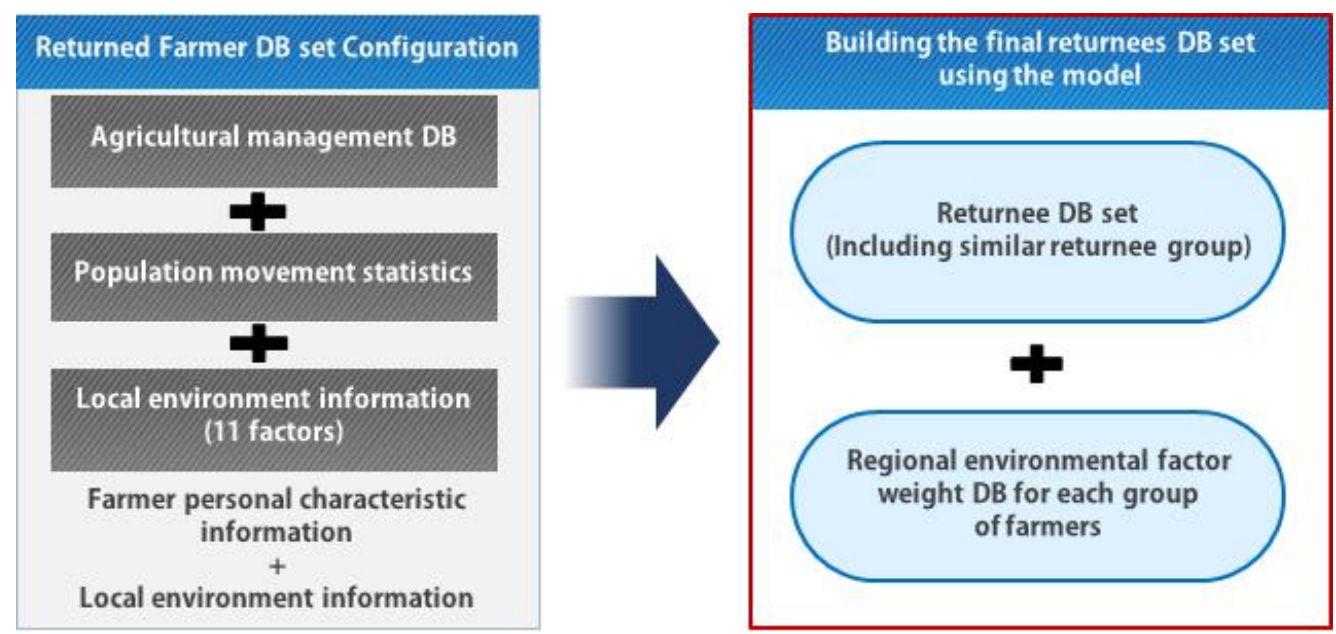

Figure 4 Final model of the returnees DB set

\section{Conclusion}

The number of returning farmers is gradually increasing due to the boom generation retirement full swing, rural life diverse life pursuit, traffic development accessibility increase. This phenomenon of returning to farming creates social benefits, and contributes to rural aging problems comprehensive development of rural regions. The government has also been recognizing the importance of the society given by the return to farming, and has been promoting since 2009 farmland and housing purchase funds loans, education, information provision various supports measures. However, there are still only a few success stories. These phenomena were analyzed as having difficulties in establishing successful return to farming due to economic instability, lack of local information, and insufficient farming experience. Therefore, there is a need to support stable returning to farming by supplementing government policies and support and providing reliable information.

Therefore, in this paper, a set of returned farmers database was constructed to provide information related to returning farmers with improved reliability and accuracy. To this end, personal characteristic information of returnees and local environmental information were linked. In addition, a set of databases for returning farmers was constructed using population movement statistics and agricultural management database. In this paper, data necessary for service development were selected and collected. In addition, a total of three types of service scenarios were created according to the type of use of returnees, and information on customized policy projects for returnees were constructed. Finally, an exploratory analysis of the collected data was conducted. In other words, refinement work was carried out to build the utilized database set, and the database set was constructed according to the purpose of use. As a result, the agricultural support information and the agricultural management body database were used based on the basic characteristic information of the returnees to provide selective customized information and establish a database set to improve reliability.

\section{References}

1. Jun IS. Effects of Returning-to-farm Related Policies on Agricultural Income of the Return Farmers by the Year of Returning. Journal of Agriculture \& Life Science. 2019;53:163-171.

2. Kim SB, Jung JH. The Determining Factors of Agricultural Income of Returning Farmers in Korea. Korean Agricultural Economics Association. 2017 Jun;58(2):69-90.

3. Choi YJ, Hwang JI, Shin HY. An Analysis of Satisfaction in the Rural Settlement of Returning Farmers. The Korean Journal of Community Living Science. 2014 Sep;25(3):321-338.

4. Ashish Choudhary, Kamala Krithivasan, Victor Mitrana. Returning and non-returning parallel communicating finite automata are equivalent. RAIRO - Theoretical Informatics and Applications. 2007 Apr;41(2):137-145.

5. Jung JH, Roh JS, Jang WC, Kim SB, Yoon KY, Kim JS. Regional Analysis of the Migration Patterns of Returning Farmers. Journal of Korean Society of Rural Planning. 2014 Dec;20(4):221-232.

6. Lee JH, Ha GS. Analysis of the Influence Factors on Satisfaction of Returning to Farming in Farmreturning and Rural-returning : With Moderating Effect of Family Factor. Asia-Pacific Journal of Business Venturing and Entrepreneurship. 2017 Oct;12(5):39-45.

7. Ann Grubbström, Camilla Eriksson. Retired Farmers and New Land Users: How Relations to Land and People Influence Farmers' Land Transfer Decisions. Sociologia Ruralis. 2018 Oct;58(4):707-725.

8. Wensong Bai, Martin Johanson, Oscar Martín Martín. Knowledge and internationalization of returnee entrepreneurial firms. International Business Review. 2017 Aug;26(4):652-665. 
9. HK De, GS Saha, Radheyshyam. Aquaculture Field School to Promote Farmer-to-Farmer Extension. Journal of Global Communication. 2013;6(2):77.

10. Lee SS, Jang WW. An Analysis of Necessity on Farmer Education by Farmer Education Sector Related to Farm Management Result. Journal of Agricultural Education and Human Resource Development. 2011 Dec;43(4):79-100.

11. Ma SJ. An Evaluation of Korean Farmer Education Policy. Journal ofAgricultural Education and Human Resource Development. 2014 Jun;46(2):23-45. 